\title{
Effect of Sympathomimetics on Gastrin Secretion from Antral G Cells in Culture
}

A. M. J. Buchan

Medical Research Council Regulatory Peptide Group, Department of Physiology, University of British Columbia, Vancouver, Canada V6T 1 W5

\begin{abstract}
Clinical data indicate that the control of gastrin secretion from the human antrum has a $\beta$-adrenergic component. The purpose of the present study was to investigate whether this was due to the presence of $\beta$-adrenergic receptors on the $G$ cells. A newly developed short-term culture system of enriched antral $G$ cells was used to eliminate the possibility of input from factors in the circulation and the peripheral innervation. The results demonstrated that epinephrine and terbutaline (a $\beta_{2}$ agonist) signifcantly stimulated gastrin release above basal which could be blocked by the addition of propranolol ( $\beta$-adrenergic antagonist). However, the $\beta_{1}$ agonist, dobutamine, and phenylepinephrine did not stimulate gastrin release above basal. In addition, simultaneous administration of epinephrine and the neuropeptide, bombesin, resulted in a potentiation of gastrin release. It was concluded that the stimulatory effect of the sympathetic system on gastrin release was mediated through $\beta_{2}$-adrenergic receptors. The data indicated that adrenaline released from the adrenal medulla and gastrin releasing peptide (the mammalian homolog of bombesin) released from the intrinsic innervation of the stomach interact with respect to the stimulation of gastrin. (J. Clin. Invest. 1991. 87:1382-1386.) Key words: dobutamine - elutriation • epinephrine • phenylepinephrine • propranolol • terbutaline
\end{abstract}

\section{Introduction}

The peptide hormones gastrin and somatostatin are known to play a significant role in the regulation of gastric acid secretion. Gastrin is one of the major stimulants of gastric acid secretion acting directly on the parietal cells. Because of the important role of these peptides in the control of gastric acid secretion it is likely that the factors controlling their release will, in turn, influence acid production.

The sympathetic system exerts a stimulatory effect on gastrin release in humans. Intravenous infusion of epinephrine results in gastrin release which is blocked by the $\beta$-adrenergic antagonist, propranolol (1). In addition, gastrin release in response to both insulin-induced hypoglycemia and distension involve adrenergic pathways $(2,3)$. The distension-induced gastrin release which is blocked by truncal vagotomy in hu-

Dr. Buchan is on sabbatical leave through May 1991 at the Department of Biochemistry, Imperial College of Science, Technology and Medicine, London SW7 2AZ, England.

Received for publication 28 June 1990 and in revised form 27 September 1990.

J. Clin. Invest.

(c) The American Society for Clinical Investigation, Inc.

$0021-9738 / 91 / 04 / 1382 / 05 \$ 2.00$

Volume 87, April 1991, 1382-1386 mans, can be suppressed by intravenous propranolol, suggesting that a $\beta$-adrenergic neural pathway under vagal control mediates gastrin release $(3)$.

The isolated perfused stomach model has been used to demonstrate that bombesin $(\mathrm{BN})^{1}$ and its mammalian homologue gastrin-releasing peptide (GRP) are potent stimuli of gastrin secretion (4-7). The major drawback in the use of whole-organ systems to study individual factors controlling endocrine cell function is the difficulty in establishing whether the observed release is the consequence of a direct action on the endocrine cells in the mucosal epithelium, an indirect effect through the extrinsic and intrinsic innervation, or via the release of an intermediate into the circulation or interstitial spaces.

In 1984 Soll et al. (8) developed a short-term, primary culture of somatostatin cells isolated from the canine fundic mucosa, which was later extended to gastrin cells from the antral mucosa (9). This preparation has confirmed that BN and GRP are potent stimuli for the release of gastrin $(9,10)$. Recently this methodology was adapted to provide a similar enriched $G$ cell preparation from human antral tissue (11). Once again BN was shown to be a potent stimulus of gastrin release from the $G$ cells in culture.

The purpose of the present study was to use this enriched preparation of human $G$ cells to investigate the effect of sympathomimetics on both basal and $\mathrm{BN}$-stimulated gastrin release. The compounds used were BN, epinephrine, phenylepinephrine, propranolol ( $\beta$-adrenergic antagonist), dobutamine $\left(\beta_{1}\right.$ agonist $)$, and terbutaline ( $\beta_{2}$-adrenergic agonist).

\section{Methods}

Cell isolation. Human antrum was obtained from 12 multiple organ donors in association with the Pacific Organ Retrieval for Transplantation System, a part of the British Columbia Transplant Society. There were seven men and five women; the average age of the males was $32 \mathrm{yr}$ and the females $41 \mathrm{yr}$. The antral vascular supply was perfused in situ with chilled Eurocollins buffer (11) with an osmolality of $355 \mathrm{mosmol} /$ $\mathrm{kg}$ and a $\mathrm{pH}$ of 7.0 , and cooled externally with crushed water-ice to minimize warm ischemic time.

The epithelial cells were isolated for culture as previously described (11). Briefly, the antral mucosa was dissected away from the submucosa and muscle layers and minced finely before separation into $10-\mathrm{g}$ aliquots. The tissue was digested in four sequential incubations. Incubation 1: $300 \mathrm{U}$ of type XI collagenase (Sigma Chemical Co., St. Louis, $\mathrm{MO}) / \mathrm{ml}$ of basal medium Eagle's for $20 \mathrm{~min}$ and after the mucosal pieces had settled the supernatant was discarded. Incubations 2-4: 300 $\mathrm{U}$ of type I and $300 \mathrm{U}$ of type XI collagenase $/ \mathrm{ml}$ of basal medium Eagle's for $1 \mathrm{~h}$, then $1 \mathrm{ml}$ of $0.5 \mathrm{M}$ EDTA (Sigma Chemical Co.) was added (final concentration $5.0 \mathrm{mM}$ EDTA) for a further $15 \mathrm{~min}$. The suspension was filtered through mesh (pore size $240 \mathrm{~nm}$, Nytex, B. H.

1. Abbreviations used in this paper: BN, bombesin; GRP, gastrin-releasing peptide; IRG, immunoreactive gastrin; \% TCC, percentage of total cell content. 
Thompson, Missisauga, ON), and the remaining fragments were subjected to another digestion. The filtered cells were centrifuged and resuspended in Hanks' balanced salt solution supplemented with $10 \mathrm{mM}$ Hepes and $0.1 \%$ bovine serum albumin (BSA, Sigma Chemical Co. radioimmunoassay grade). The cell suspensions collected from digests 2,3 , and 4 were combined and filtered through a fine Nytex mesh (pore size $62 \mathrm{~nm}$ ) to remove large aggregates.

The cell suspension was separated according to cell size by passage through an elutriator rotor (model J-21, with a chamber volume of 5 $\mathrm{ml}$, Beckman Instruments, Inc., Palo Alto, CA). The cells $\left(1.5 \times 10^{8}\right)$ were loaded into the chamber at a flow rate of $25 \mathrm{ml} / \mathrm{min}$ and a centrifuge speed of $2,500 \mathrm{rpm}$. The cells in the chamber were washed by a flow of sterile medium for $3 \mathrm{~min}$ (total volume $75 \mathrm{ml}$ ) to remove bacteria and cell fragments, and then $100 \mathrm{ml}$ was collected in sterile tubes at a flow rate of $40 \mathrm{ml} / \mathrm{min}$ with a centrifuge speed of $2,100 \mathrm{rpm}$.

Cell culture. The cells collected were resuspended at $1 \times 10^{6}$ cells/ $\mathrm{ml}$ in a tissue culture medium comprising Dulbecco's modified Eagle's (DME, Gibco Laboratories, Grand Island, NY) with $5.5 \mathrm{mM}$ glucose and supplemented with $50 \mu \mathrm{g} / \mathrm{ml}$ gentamicin, $2 \mathrm{mM}$ glutamine, $1 \mu \mathrm{g} /$ $\mathrm{ml}$ hydrocortisone (Sigma Chemical Co.), $8 \mu \mathrm{g} / \mathrm{ml}$ insulin (Sigma Chemical Co.), $5 \mathrm{ng} / \mathrm{ml}$ nerve growth factor (Collaborative Research, Inc., Waltham, MA), and 5\% human serum. The cells were plated at this density on 24-well collagen-coated plates (Costar Data Packaging, Cambridge, MA) and maintained at $37^{\circ} \mathrm{C}$ for $48 \mathrm{~h}$ in a humidified atmosphere with $5 \% \mathrm{CO}_{2}$.

Release studies. The wells were washed twice in the release medium (DME with $4.4 \mathrm{mM}$ glucose, $0.1 \% \mathrm{BSA}$ ) to remove floating cells and debris. The adherent cells were incubated in $975 \mu$ l of release medium to which the secretagogues were added in $25-\mu$ l aliquots of a 40 -fold concentrated solution kept cooled on ice. The control incubations involved addition of $25 \mu \mathrm{l}$ of ice-cold release medium. After $120 \mathrm{~min}$ at $37^{\circ} \mathrm{C}$, the medium was aspirated and centrifuged for $1 \mathrm{~min}$ to remove particulate matter. The supernate was stored at $-20^{\circ} \mathrm{C}$ for radioimmunoassay. The cells from control wells were extracted by boiling in distilled $\mathrm{H}_{2} \mathrm{O}$ for $10 \mathrm{~min}$ and centrifuged to remove cell debris, and the supernate was stored at $-20^{\circ} \mathrm{C}$.

Secretagogues. BN was purchased from Institut Armand-Frappier (Montreal, Canada). Epinephrine, phenylepinephrine, and propranolol were obtained from Sigma Chemical Co.; dobutamine hydrochloride was obtained from Eli Lilly \& Co., Toronto, Ontario; and terbutaline sulphate was a kind gift from Astra Pharmaceuticals (Sweden).

Radioimmunoassay. Immunoreactive gastrin (IRG) concentrations in the supernatants and cell extracts were measured by specific radioimmunoassay employing synthetic human gastrin I (Research Plus Inc., Bayonne, NJ) as standard. Gastrin antibody CKG2 (MRC Regulatory Peptide Group, Vancouver) was used in the assay at a final dilution of $1: 2,500,000$. This antibody binds to amino-terminal residues and recognizes gastrin 17 only (11).
Expression of results. IRG was initially determined in picograms per milliliter. IRG release was further expressed as percentage of total cell content (\% TCC) owing to considerable inter-donor variation. Statistical significance was determined using the paired Student's $t$ test.

\section{Results}

Epinephrine-stimulated gastrin release. In cells isolated from seven donors, the effect of a concentration range of epinephrine from $10^{-8}$ to $10^{-4} \mathrm{M}$ on gastrin secretion was examined. Basal gastrin release was shown to be $1.3 \pm 0.2 \%$ TCC. Epinephrine at concentrations $<10^{-6} \mathrm{M}$ did not significantly stimulate gastrin levels above basal. At $10^{-5} \mathrm{M}$ the maximal response was threefold above basal $(3.5 \pm 0.7$ vs. $1.3 \pm 0.2 \%$ TCC, $P<0.05)$. Addition of propranolol, a $\beta$-adrenergic antagonist, at $10^{-6} \mathrm{M}$ inhibited epinephrine release in a competitive manner, shifting the concentration response curve to the right (Fig. $1 a$ ).

Effect of phenylepinephrine on gastrin release. In cells isolated from five donors the effect of phenylepinephrine at concentrations from $10^{-8}$ to $10^{-5} \mathrm{M}$ did not stimulate gastrin release above basal (Fig. 1 b). At the highest concentration tested $\left(10^{-5} \mathrm{M}\right)$ phenylepinephrine resulted in the release of $1.7 \pm 0.3 \%$ TCC which was not significantly different from the basal level $(1.1 \pm 0.2 \%$ TCC).

Terbutaline sulphate-stimulated gastrin release. In cells isolated from five donors the effect of a concentration range of the $\beta_{2}$-adrenergic agonist, terbutaline was examined. Basal gastrin release was $1.0 \pm 0.2 \%$ TCC. Terbutaline was 10 -fold more potent than epinephrine causing significant stimulation of gastrin release at $10^{-7} \mathrm{M}$. Maximal stimulation at $10^{-6} \mathrm{M}$ resulted in a 2.5 -fold increase over basal $(2.3 \pm 0.4$ vs. $1 \pm 0.2 \%$ TCC, $P$ $<0.05)$. The observed response was inhibited in a competitive manner by the addition of the $\beta$-adrenergic antagonist, propranolol, at $10^{-6} \mathrm{M}$ (Fig. 2 a).

Effect of dobutamine hydrochloride on basal gastrin release. The effect of a concentration range of dobutamine hydrochloride was examined on cells isolated from three donors. Dobutamine hydrochloride at the highest concentration tested resulted in a nonsignificant inhibition of gastrin release; basal: $1.9 \pm 0.2$ vs. $10^{-5} \mathrm{M}$ dobutamine hydrochloride: $1.6 \pm 0.3 \%$ TCC (Fig. $2 b)$.

Effect of epinephrine on $B N$-stimulated gastrin release. Addition of $\mathrm{BN}$ at concentrations ranging from $10^{-14}$ to $10^{-8} \mathrm{M}$
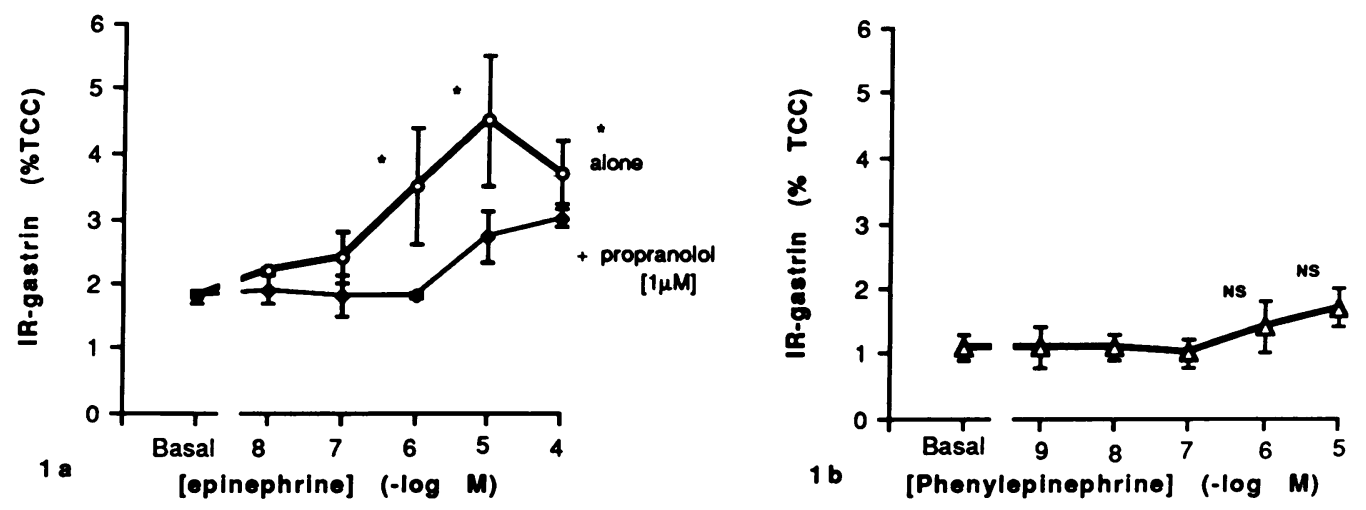

Figure 1. (a) The effect of a concentration range of epinephrine on gastrin release. The maximum response was seen at $10^{-5} \mathrm{M}$ epinephrine. ${ }^{*} P<0.05$ compared to basal release. Addition of propranolol at $10^{-6} \mathrm{M}$ resulted in a rightward shift in the concentration-response curve. $(b)$ The addition of a concentration range of phenylepinephrine to similar cultures did not significantly stimulate gastrin release. 

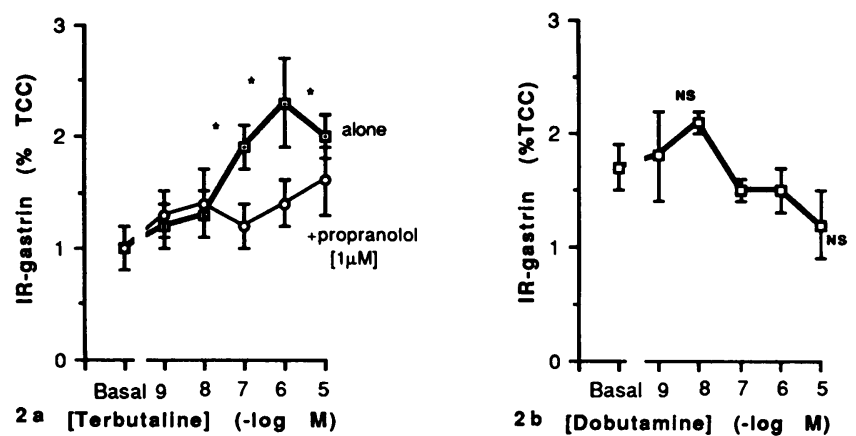

Figure 2. (a) The effect of a concentration range of terbutaline on gastrin release. The maximum response was observed at $10^{-6} \mathrm{M}$. ${ }^{*} P$ $<0.05$ compared to basal release. Addition of propranolol at $10^{-6} \mathrm{M}$ resulted in a rightward shift in the concentration-response curve. (b) The addition of a concentration range of dobutamine did not result in a stimulation of gastrin release. At the highest concentration tested there was a nonsignificant inhibition of basal gastrin release.

resulted in a concentration dependent increase in gastrin release. Simultaneous addition of epinephrine $\left(10^{-6} \mathrm{M}\right)$ to the release medium resulted in a significant augmentation of gastrin release (Fig. 3). Maximal BN-stimulated gastrin release at $10^{-8} \mathrm{M}$ was increased 2.5-fold (BN alone $7.4 \pm 1.1 \%$ TCC, with epinephrine $18.5 \pm 3.2 \%$ TCC, $P<0.05$ ). Addition of propranolol at $10^{-6} \mathrm{M}$ reversed the augmentation observed by the addition of epinephrine $\left(10^{-6} \mathrm{M}\right)$ to levels not significantly different to that observed in the presence of $\mathrm{BN}$ alone (Fig. 3).

Epinephrine alone at $10^{-7} \mathrm{M}$ did not significantly stimulate gastrin release, however, in combination with the lowest concentration of $\mathrm{BN}\left(10^{-14} \mathrm{M}\right)$ it resulted in a potentiation of gastrin release. The observed release being significantly greater

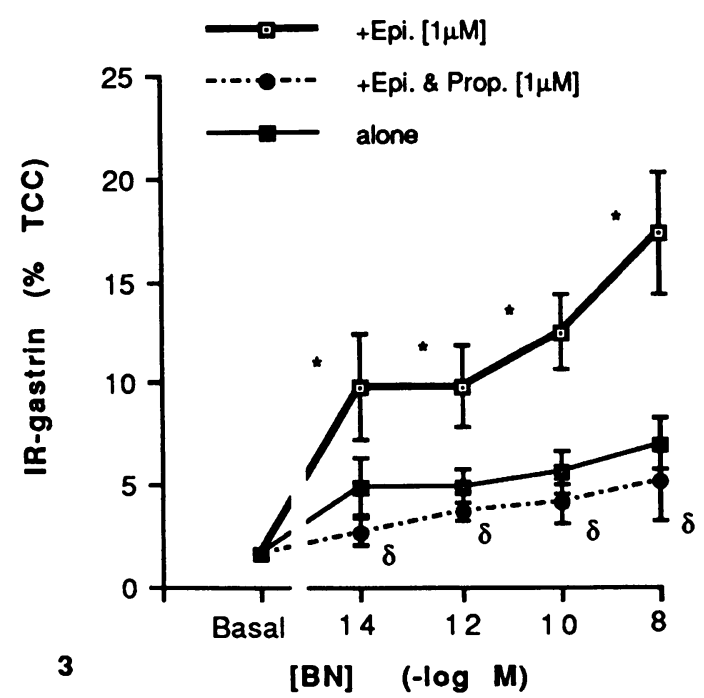

Figure 3. Addition of epinephrine at $10^{-6} \mathrm{M}$ to a concentration range of $B N$ resulted in a significant increase in the amount of gastrin released. ${ }^{*} P<0.05$ compared to the effect of $\mathrm{BN}$ alone. The effect of the addition of epinephrine on $\mathrm{BN}$-stimulated gastrin release was reversed by the addition of propranolol $\left(10^{-6} \mathrm{M}\right){ }^{8} \mathrm{NS}$ compared to the effect of $\mathrm{BN}$ alone. than the sum of the release induced by the two compounds alone (Fig. $4 a$ ).

Simultaneous addition of epinephrine at $10^{-6}$ and $10^{-5} \mathrm{M}$ resulted in a similar potentiation of $\mathrm{BN}$-stimulated gastrin secretion (Fig. 4, $b$ and $c$ ). The greatest response was seen after the addition of $10^{-5} \mathrm{M}$ epinephrine with $10^{-8} \mathrm{M} \mathrm{BN}$, resulting in a threefold increase above that observed after addition of the two secretagogues alone (simultaneous addition, $21.5 \pm 3.9 \%$ TCC; summation of $\mathrm{BN} 10^{-8} \mathrm{M}$ and epinephrine $10^{-5} \mathrm{M}, 7.3 \pm 0.9 \%$ TCC, $P<0.01$ ).

\section{Discussion}

Addition of the adrenergic agonists, epinephrine and terbutaline, to the antral cultures resulted in a concentration-dependent stimulation of gastrin release. The maximum response in both cases was a two- to threefold increase above basal. The release of gastrin generated by the addition of the two agonists was competitively inhibited by the addition of propranolol, a $\beta$-adrenergic antagonist at $10^{-6} \mathrm{M}$. The addition of the $\beta_{1}$ agonist, dobutamine, did not stimulate gastrin release above basal. These data confirm the clinical findings of Stadil and Rehfeld (1) and indicate that the response to adrenergic stimulation is due to the presence of $\beta_{2}$ receptors on the gastrin cells.

The cell preparation used in the present study contains 20$30 \%$ gastrin, $1-5 \%$ somatostatin, and $60-65 \%$ gastric mucin cells (11). The addition of a somatostatin antibody to the cell cultures does not significantly alter basal gastrin secretion (11). During the present study the same antibody was added with the addition of terbutaline and it did not significantly alter the resultant gastrin release (data not shown). Therefore, the effect of the $\beta$-adrenergic agonists does not involve inhibition of a tonic control of gastrin release via somatostatin.

Adrenaline produced by the adrenal medulla has a higher affinity for the $\beta_{2}$ receptor than noradrenaline produced by the neurons of the sympathetic nervous system, suggesting that changes in the circulating levels of adrenaline may directly influence gastrin secretion. The present study demonstrated that the $\alpha$-adrenergic agonist, phenylepinephrine, did not significantly affect basal gastrin release, indicating that noradrenaline is unlikely to have a stimulatory effect on gastrin release. The observation that circulating catecholamines have been demonstrated to stimulate the release of glucagon from the pancreatic islets would support an endocrine role for adrenaline resulting in direct stimulation of endocrine cells (12).

Insulin-induced hypoglycemia is known to be a powerful stimulus for gastrin release in human (13) that is not blocked by vagotomy (14). Owing to the inability of vagotomy to completely reverse gastrin release in response to hypoglycemia, circulating catecholamines acting through a $\beta$-adrenoreceptor have been implicated (15). However, typical resting venous levels of adrenaline are $1 \mathrm{pmol} /$ liter rising to around $1 \mathrm{nmol} /$ liter during heavy exercise and hypoglycemic shock (16). A study of the effect of heavy exercise in a group of 11 healthy volunteers demonstrated maximal epinephrine levels of 1 nmol/liter. During the exercise there was a small but nonsignificant increase in plasma gastrin. Of greater interest was the fact that when the same volunteers received an infusion of epinephrine which increased levels to $5 \mathrm{nmol} /$ liter (with unchanged norepinephrine levels) there was a significant rise in plasma 

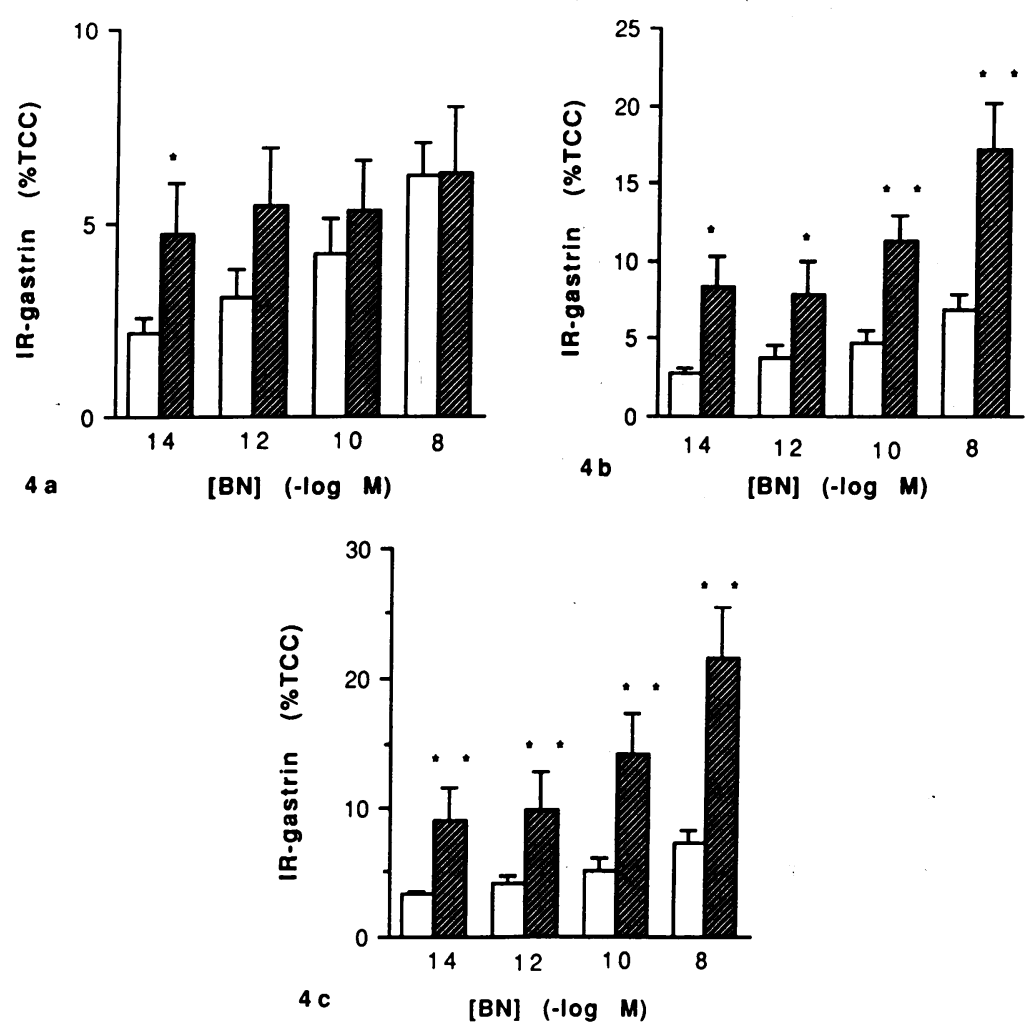

Figure 4. (a) The effect of the addition of epinephrine at $10^{-7} \mathrm{M}$ on BN-stimulated gastrin release. The data is expressed as percent release above basal. ${ }^{*} P<0.05$ compared to the effect of BN alone. (Open bars) BN alone; (hatched bars) $\mathrm{BN}+$ epinephrine $(b)$ The effect of the addition of epinephrine at $10^{-6} \mathrm{M}$ on $\mathrm{BN}$ stimulated gastrin release. ${ }^{*} P<0.05 ;{ }^{* *} P<0.001$ compared to the effect of $\mathrm{BN}$ alone. (c) The effect of the addition of epinephrine at $10^{-5} \mathrm{M}$ on BNstimulated gastrin release. ${ }^{* *} P<0.001$ compared to BN alone.

gastrin (17). In the present study, $10^{-6} \mathrm{M}$ epinephrine was required before a significant increase in gastrin release was observed, which is 1,000 -fold greater than the levels observed in the circulation. This difference may be due, in part, to the fact that epinephrine is unstable in solution.

Terbutaline, a more stable analogue of adrenaline, was capable of initiating gastrin release at concentrations between 10 and $100 \mathrm{nmol} /$ liter, bringing the concentration required closer to physiological levels. An additional factor is that venous measurements are taken after transit through the liver and kidney major sites of adrenaline clearance. A recent study has demonstrated that mean arterial levels of adrenaline were two- to threefold higher than venous levels (18). It is probable that circulating adrenaline secreted from the adrenal medulla is a physiological stimulus for gastrin secretion, especially during hypoglycemic shock.

BN has been demonstrated to be a potent stimulus for gastrin release both in vivo and in vitro in similar isolated cell preparations (9-11). Activation of $\mathrm{BN}$ receptors is associated with stimulation of the protein kinase $C$ pathway (9), whereas the action of epinephrine at the $\beta$-receptor is usually coupled to increased levels of cyclic adenosine monophosphate (19). The possibility that the adrenergic agonists would interact with bombesin to increase gastrin release in a synergistic manner was investigated.

In the present experiments addition of $\mathrm{BN}$ alone caused a maximal response of fivefold above basal. Epinephrine alone at $100 \mathrm{nmol} /$ liter did not stimulate gastrin release. However, addition of this concentration concomitant with $10^{-14} \mathrm{M}$ BN resulted in a doubling of the gastrin secreted in response to $10^{-14}$ $\mathrm{M} B \mathrm{BN}$ alone. The addition of epinephrine at $10^{-6}$ and $10^{-5} \mathrm{M}$ resulted in a significant potentiation of BN-stimulated gastrin secretion at all concentrations of $\mathrm{BN}$ tested.

The results obtained indicate that there is an interaction between adrenaline released from the adrenal medulla and BN released from intrinsic neurons within the stomach wall to potentiate gastrin release. GRP, the mammalian homologue of $\mathrm{BN}$, has been demonstrated to be released after vagal stimulation (20) and is present in nerve terminals adjacent to $G$ cells in the antral mucosa (21). The synergistic effect of BN and epinephrine may be the mechanism underlying the reported $\beta$ adrenergic pathway under vagal control seen during distension-induced gastrin release (3).

\section{Acknowledgments}

The technical assistance of Mrs. N. Duleba and Mr. A. Yu is gratefully acknowledged. I would also like to thank Dr. M. Meloche, Department of Surgery, for providing the samples through the Pacific Organ Retrieval for Transplantation (PORT) programme.

This work was supported by a Medical Research Council of Canada Group Grant in Regulatory Peptides.

\section{References}

1. Stadil, F., and J. R. Rehfeld. 1973. Release of gastrin by epinephrine in man. Gastroenterology. 65:210-215.

2. Christensen, K. C., and F. Stadil. 1976. On the beta adrenergic contribution to gastric acid and gastrin responses to hypoglycaemia in man. Scand. J. Gastroenterol. Suppl. 37:81-86.

3. Peters, M. N., J. H. Walsh, J. Ferrari, and M. Feldmen. 1982. Adrenergic regulation of distention-induced gastrin release in humans. Gastroenterology. 82:659-663. 
4. Bertaccini, G., V. Erspamer, P. Melchiorri, and N. Sporanzi. 1974. Gastrin release by bombesin in the dog. Br. J. Pharmacol. 52:219-225.

5. Martindale, R., G. Kauffman, S. Levin, J. H. Walsh, and T. Yamada. 1982. Differential regulation of gastrin and somatostatin secretion from isolated, perfused rat stomachs. Gastroenterology. 83:240-244.

6. Schubert, M. L., and G. M. Makhlouf. 1987. Neural regulation of gastrin and somatostatin secretion in rat gastric antral mucosa. Am. J. Physiol. 253 (Gastrointest. Liver Physiol. 16):G721-G725.

7. Holst, J. J., S. Knuhtsen, C. Orskov, T. Skak-Nielsen, S. S. Poulsen, and O. V. Nielsen. 1987. GRP-producing nerves control antral somatostatin and gastrin secretion in pigs. Am. J. Physiol. 253 (Gastrointest. Liver Physiol.) 16:G767-G774.

8. Soll, A. H., T. Yamada, J. Park, and L. P. Thomas. 1984. Release of somatostatin-like immunoreactivity from canine fundic mucosal cells in primary cultures. Am. J. Physiol. 247 (Gastrointest. Liver Physiol.) 10:G558-G566.

9. Giraud, A. S., A. H. Soll, F. Cuttitta, and J. H. Walsh. 1987. Bombesin stimulation of gastrin release from canine gastrin cells in primary culture. Am.J. Physiol. 252 (Gastrointest. Liver Physiol.) 15:G413-G420.

10. Sugano, K., J. Park, A. H. Soll, and T. Yamada. 1987. Stimulation of gastrin release by bombesin and canine gastrin-releasing peptides. J. Clin. Invest. 79:935-942.

11. Campos, R. V., A. M. J. Buchan, M. Meloche, R. A. Pederson, Y. N. Kwok, and D. H. Coy. 1990. Gastrin secretion from human antral G cells in culture. Gastroenterology. 99:36-44.

12. Young, J. B., and L. Landsberg. 1983. Adrenergic influences on peripheral hormone secretion. In Adrenoceptors and Catecholamine Action. Part B. G. Kunos, editor. John Wiley \& Sons, Inc., New York. 157-217.

13. Brandsborg, O., M. Brandsborg, and N. J. Christensen. 1975. Plasma adrenaline and serum gastrin: studies in insulin-induced hypoglycemia and after adrenaline infusions. Gastroenterology. 68:455-460.

14. Stadil, F. 1972. Effect of vagotomy on gastrin release during insulin hypoglycaemia in ulcer patients. Scand. J. Gastroenterol. 7:225-231.

15. Brandsborg, O., M. Brandsborg, and N. J. Christensen. 1978. The role of the $\beta$-adrenergic receptor in stimulation of gastrin: studies in normal subjects and in patients with duodenal ulcer. Eur. J. Clin. Invest. 6:202-206.

16. Cryer, P. E. 1980. Physiology and pathophysiology of the human sympathoadrenal neuroendocrine system. $N$. Engl. J. Med. 303:436-444.

17. Monnikes, H., H. Koop, K. Ehlenz, J. Dionysius, and R. Arnold. 1989. Role of circulating catecholamines in the control of pancreatic polypeptide and gastrin release. Res. Exp. Med. 189:181-187.

18. Halter, J. B., E. Pflug and A. G. Tolas. 1980. Arterial-Venous differences of plasma catecholamines in man. Metab. Clin. Exp. 29:9-12.

19. Limbird, L. E. 1981. Activation and attenuation of adenylate cyclase: the role of GTP-binding proteins as macromolecular messengers in receptor-cyclase coupling. Biochem. J. 195:1-13.

20. Nishi, S., Y. Seino, J. Takemura, H. Ishida, M. Seno, T. Chiba, C. Yanaihara, N. Yanaihara, and H. Imura. 1985. Vagal regulation of GRP, gastric somatostatin and gastrin secretion in vitro. Am. J. Physiol. 248:E425-431.

21. Jain, D. K., M. M. Wolfe, and J. E. McGuigan. 1985. Functional and anatomical relationships between antral gastrin cells and gastrin-releasing peptide neurons. Histochemistry. 82:463-467. 